\title{
Arts practice and research: locating alterity and expertise
}

In the United Kingdom, practice-based research has been the subject of pedagogic debate for a quarter of a century, in particular in the context of both the study methods and the adjudication of higher research degrees.

For example, since the1992 reform of the higher education system in Britain, represented by the first Research Assessment Exercise (RAE1), new higher degrees in fields of cultural study involving practical or technical traditions, such as Art, Design, Architecture and the Performing Arts, have been created and rationalised according to templates derived from the study of history and theory. These qualifications are intended to create parity between degrees pursued by practical and cross-disciplinary methods and those that already existed to establish theoretical competence.

Therefore, practice-based higher qualifications in Britain are the result of historical changes in the structure of higher education, bringing traditions of practice into the established context of theoretical research (Bird 2000:03).

Debates about the role of practice in research have been underpinned by the subsequent proliferation of these qualifications. Relative to the structure of theoretical degrees, or those that focus on the adjudication of text, problems arise in the use of practical methods and the production of research outputs in forms other than text.

These problems are not unique to higher education, but early attempts to address them developed largely in response to the instrumental issues of adjudicating research and awarding qualifications (Cornock 1988, Allison 1988, Frayling 1993, Gray 1993). 
There is still no agreed pedagogic definition of practice-based research in the visual and performing arts in Britain (Candy 2006:03). A report of the country's Arts and Humanities Research Council, revised in 2008 , could not identify ' ... any established or accepted prior definition...' (Rust, Mottram and Till 2008:10).

This lack of definition both reflects and accounts for problems articulating agreed methodologies for practice-based research and adjudicating its outputs. Almost ten years after the emergence of the first practice-based qualifications, educationalist Fiona Candlin wrote that students, supervisors and examiners are ' ...still expected to proceed without a clear map of what is expected and without established criteria for competence.' (Candlin 2000:04).

There is not a dearth of definitions, however, but rather a wide variety, predicated upon the developing programmes of individual places of study. Candlin identifies an extreme diversity of required research outputs, from the visual-only outputs required by Leeds Metropolitan University's PhD by Visual Practice on one hand, to the requirement at the University of Hertfordshire for a written thesis of eighty thousand words to accompany visual material, on the other (Candlin 2000).

This also arises from the incorporation of traditions belonging to particular media into the requirements for assessment of particular degrees. 'In the case of PhDs by Composition at the University of Edinburgh, the outcome... is a portfolio of compositions... No written component is required.' (Coyne and Triggs 2007:03).

This practical diversity of definitions could provide a discursive opportunity wherein debate about the functions and status of the expressive forms of theses formed an 
aspect of study. However, a seeming lack of confidence in articulating current knowledge of the relationships between theory and practice appears to result in both a lack of consensus and a reluctance to embed mutability or discourse in the structure of $\mathrm{PhD}$ study itself.

As well as a lack of agreement about outputs, and hence a lack of agreement about the adjudication of these outputs, there is also lack of agreement over the terminology used to describe the methodological role of practice.

The term 'practice-based' is widely used to describe the use of practice as a method of research, and its products as research outputs in themselves, not requiring the mediation of a text (Candy 2006:01). The term 'practice-led', on the other hand, refers to the processes and products of practice as topics for theoretical analysis utilising text, so that '.. the results of practice-led research may be fully described in text form without the inclusion of a creative work.' (Candy 2006:01).

However, consensus over these terms is not complete. As recently as 2008, the revised Arts and Humanities Research Council report into practice as research used the term 'practice-led' to mean the use of practice as research method rather than as the topic of research (Rust, Mottram and Till 2008:10).

Candy writes: ' $\ldots$ whilst the significance and context of the (research) claims are described in words, a full understanding can only be obtained with direct reference to the outcomes.' (Candy 2006:01). There are specific methodological problems with this definition, but the identification of two distinct approaches to practice as research, in which one definition focuses on method and the other definition focuses on topic, creates 
a framework for further discussion.

The diversity of definitions of both methods and outputs is derived as much from a continuing debate on theoretical questions, arising out of debates about the practical issues of teaching and assessing research degrees.

Three theoretical questions underpin the debates. First, are non-text outputs, and the methods of their production, able to communicate knowledge rather than simply constituting knowledge? Second, by what criteria can this knowledge be adjudicated within an academic environment? Third, what is the status of these outputs and methods relative to the production of text?

Discussion about the ways in which artefacts communicate knowledge as research outputs is underpinned by different conceptions of intentionality and interpretation. Explicit in Leeds Metropolitan University's requirement for visual-only outputs is the idea that material produced in practice is completely intentioned and can be clearly interpreted and adjudicated for competence without reference to an accompanying text.

This view is supported by arguments against the intentionality of text rather than arguments that make explicit how non-text artefacts communicate. The intentionality of both text and artefacts is considered mutable, but no evaluation of the ways in which mutability is a basis for adjudicating academic competence is forthcoming (Candlin 2000).

This position is predicated upon the idea that artefacts presented as outputs require an interpretative framework, but that this framework is centred upon the artefact 
itself. The issue is about the artefact relative to interpretation rather than the artefact relative to intentionality.

Many participants in the debate argue that interpretation cannot be adjudicated in this sense and hence artefacts cannot independently communicate knowledge as research outputs (Higher Education Quality Council 1997:05, Burling, Freidman and Gutherson 2002:10).

As a result, for some of these educationalists, the interpretative framework for artefacts is provided by text, refocusing the terms of adjudication upon the intentionality of the researcher relative to their own production (Newbury 1996, Candlin 2000:02, Rust, Mottram and Till 2007:12).

This creates a situation unique in humanities research, although not in the instrumental research undertaken in science or technology. In this situation, the researcher is both producer and commentator, effectively undertaking a dual practice where process and products are methods of research to be studied as they occur, rather than the outputs of study alone (Quinn 2007).

However, others retain a focus on interpretation, arguing that establishing professional consensus will provide an interpretative framework for artefacts as outputs, independent of text. Following Anne Douglas, Karen Scopa and Carole Gray, Michael Biggs argues that developing an agreed interpretative framework for practical outputs is the role of the institution or rather, of educators precisely identifying their community of expertise (Douglas, Scopa, Gray 2000:03, Biggs 2002:04). Candlin writes: 'To become an expert, you have to have a specialised field, which can only be mastered if it is 
enclosed, or defended if its borders are clearly defined and policed.' (Candlin 2000: 02)

Possibly, an opportunity presents itself here. Whilst expertise, and hence adjudication, is defined by agreed bodies of knowledge and methodologies, it might be plausible to argue that the relationship between theory and practice generates a field of expertise in itself. In this sense, discussions about the relationship between theory and practice that are informed by a wide range of approaches in the field could themselves constitute a required aspect of doctoral study. This elides the problems represented by differences between the expressive forms of theses, as long as the elision becomes a meta-theme of the study itself.

Approaches to interpretation have attempted to identify a unique role for practice that cannot be achieved by a return to the intentionality of text alone or through the process of managing a dual practice. Stephen Scrivener has identified this unique role in what he describes as 'creative-production' (ie. a tradition of studio practice), requiring the representation of the researcher's personal journey in practice as a template for future studio practitioners to follow (Scrivener 2000:02).

The detailed recording and reporting of the practical processes of production and reflection are necessary for practice to fulfil this role. Text is then descriptive rather than analytical, outlining methods of production as an adjunct to the research outcomes, which remain the artefacts themselves (Scrivener 2000:09).

Scrivener arrives at the 'creative-production' model, requiring recording and reporting, because he makes a distinction between traditional studio processes and instrumental or problem solving models of learning, utilised in science and design, such 
as those developed by educationalist Donald Schön (Schön 1983).

Schön describes the process of problem solving as cyclical. A problem cannot be solved until it is suitably set, he argues. Each new form of a problem is a critique that outlines the problem in a new way. Experiments test the newly outlined problem and finally, unintended experimental outcomes change the problem, leading back to the start of the cycle. Further, judgements about the value of choices made throughout the cycle are made in terms of past experience (Schön 1983:139).

Scrivener argues that although the process of problem solving offers repeatable templates for adjudicating artefacts, as well as devising practice methods, these templates cannot encompass the experience of studio practice (Scrivener 2000:05). In his opinion, the 'creative-production' researcher is motivated by the desire for practical activity per se, rather than by the desire to frame and solve problems to an adjudicated template in order to communicate results. This desire will not submit to analysis, but can only be described and adjudicated as a template for further action (Scrivener 2000:02).

Biggs, Burling, Freidman and Gutterson are critical of this interpretative framework on the grounds that, although the model can be generalised, there is no way in which to adjudicate the relative competence of individual practices or researchers. It can only describe practice on the assumption that the description will be significant to other practitioners, rather than creating a repeatable framework for analysis in each case. Biggs writes: 'We need to differentiate between... personal development... and activities that are significant for others.' (Biggs 2002:02, Burling, Freidman and Gutterson 2002:14). 
However, although Scrivener proposes the 'creative-production' template, aspects of Schön's problem solving model convince him. He sees the possibility of considering the outputs of problem solving as demonstrations of process, rather than as entirely instrumental outcomes that finally leave process behind (Scrivener 2000:07).

In this sense, some practical outputs are able to provide a view on their own production. They might appear alongside both descriptive and analytical text, but neither type of text is necessary for them to communicate as well as constitute knowledge. The production of these artefacts is directed as problem solving, but the outputs are not entirely instrumental. Rather they are demonstrative.

As demonstration, these outputs create an interpretative framework that derives from the setting of a problem itself. They represent a type of problem solving that aims to make its processes explicit in its outputs rather than aiming to effect change with the output as the solution to a problem. Douglas, Scopa and Gray write '...the outcomes of the research process are... evidenced... within the final product.' (Douglas, Scopa and Gray 2000:03).

In this sense, Douglas, Scopa and Gray write ' $\ldots$ the role of practice is part of the methodology of the research and is therefore relative and heuristic...' (Douglas, Scopa and Gray 2000:05). They identify two possible roles for practice in research, according to a problem solving model generating outputs that communicate the process of their own production: either as evidence in support of a theoretical argument presented as text, or as a means of communicating knowledge that text cannot, through demonstration (Douglas, Scopa and Gray 2000:05). 
The studio drawings that I will discuss later in this paper constitute solutions to two specific problems framed so that the drawings themselves demonstrate the process by which the problems are solved.

They do this by making overt visual comparisons between themselves and existing drawings made by other studio practitioners that contribute to a history of already-seen artworks. Conceiving these comparisons in theory was as important to the framing of the two problems as it is to an understanding of the drawings as outputs or solutions. They were not conceived through practice. That is, the drawings respond to two questions that were, in themselves, framed in order to allow their solutions to communicate knowledge as practical outputs.

This process did not preclude the use of descriptive, theoretical or analytical text. However, theory predicated and framed each problem and theorising was not undertaken post hoc: the drawings themselves take a theoretical position. Neither do any descriptions I include constitute a dual approach in themselves. Nor were the drawings approached as a predetermined topic to be researched and analysed in text alone.

The pedagogical debates about practice-based research reveal wider issues about the relationship between theory and practice as types of activity, where theory is circumscribed by the medium of text and practice is defined broadly as not-text.

However, I propose that interrogation of these definitions will advance little in discussions that focus on media. Text or not-text is beside the point. Rather, the relationship between theory and practice can be explored as a relationship between intentionality and alterity, based in an essentially social conception of communities of 
expertise, including academic communities of expertise. As Douglas, Scopa and Gray write: 'Embodied knowledge within the artwork relies on the ability of the research community to understand the particular artwork and the research within it.' (Douglas, Scopa and Gray 2000:03).

Is it possible to describe any types of drawings as theoretical drawings? The term is unfamiliar to any number of communities of expertise who know theoretical text or theoretical diagrams, which are types of drawing.

An example of a type of theoretical drawing is provided by artist Scott McCloud's theory of communication in comic strips, drawn as a comic strip. The theory is part of the comic's script and the comic strip register is used to extrapolate that script (McCloud 1993:180). The comic strip register acts as an intentioned text, for all that it includes drawings as well as words.

Alternatively, both the comic strips of Robert Sikoryak and Matt Madden take theoretical positions in which the alterity of a reader is a constituent part. There is no explanatory text in either artists' work, because the drawings themselves communicate a point of view in relation to a predetermined theoretical problem. They are meta-comics, employing a comparative positioning that requires a specific community of expertise in order to be understood (Sikoryak 2009, Madden 2007).

McCloud insists on the distinction between message and medium. For him, both theory and practice are defined by different approaches to the roles that message and medium fulfill. Theory is a type of communication in which medium and message are never confused, and in which the role of medium is consensually ignored by theoreticians 
and readers. The agreed focus is upon theory's object, which is what is communicated in the text. The medium is transparent. Meaning is approached as an object in the text.

Consequently, a characteristic of theory is its pretence to absolute intentionality. In theory, meaningfulness resides only in the content of the text. It is not communicated in the material of the text, nor in the relationships represented by the text's production, nor through the interaction of productive intentionality and receptive alterity on the part of subjective writers and readers.

Even if a theoretical text is difficult, those belonging to the community of knowledge to which it is directed will not look outside its content in order to understand it. They agree that everything they need in order to understand it must be found in the content of the text, because they agree on the text's absolute intentionality.

However, we do not approach drawings in the same way as we approach theoretical text. Why not? First, we agree with each other that we approach the two forms of communication differently. Drawing belongs to a different register of communication to writing. This difference in register is created by the consensual adoption of a different set of rules of engagement. As a result, we cannot find the whole meaning of the drawing in the content of its text because there is no objectified 'text' in the drawing in this sense. There is no agreed absolute intentionality for us to focus upon.

Instead, we agree to find meaning in a more complex relationship between intentionality and alterity, represented in the physical medium of the drawing. Unlike objectified theoretical text, we agree upon the inclusion of the subjectivity of producers and receivers in finding meaning in the medium and in the social situation of drawings. 
Theorising is not drawing. Not only is this because theoretical text and drawing are materially different, but also because in making and consuming theory, we agree to the absolute intentionality of the text. This is not at all the agreement that makers of drawings have with viewers of drawings. With drawings, the medium itself is agreed to be communicative, so that the relationship between intentionality and alterity is meaningful in itself.

Some of the confusion about practice-based research derives from confusion about the different roles of message and medium that are defined by our consensually agreed approaches to theory on one hand and practice on the other hand.

Pedagogically, it might only be by considering the role of theory from the position of the role of practice, whilst maintaining the active possibility of both, that learning takes place. Practice-based research can manipulate these different points of view with the aim of mutual enlightenment. The search for agreed models for this process is the wider subject of debate in the field (Coyn and Triggs 2007:04).

According to the options I have considered briefly in this paper, if we agree the conventions of research and bring them to bear upon practice, we could make and look at drawings in a different way, adjudicating their meaning within an agreed field of expertise.

For example, we could maintain a self-conscious oscillation between the agreed conventions of the two pursuits as both producers and readers, following Quinn's dual practice model.

We could first approach drawings as though they elide intentionality and 
interpretation, as though they comprised theoretically objective content. Then we could attempt to approach this theoretical stance itself in terms of our conventional approach to drawings, bringing form and situation into a now wholly theoretical reading of the drawing and, as a consequence, bringing subjectivity into view. In this way, we could read drawings absolutely, whilst being enabled to consider the whole form of the drawing as theory, not only a theoretically objectified content.

In 2010, I made a series of drawings that attempted to answer a research question. I approached drawing in terms of theory's conventions and therefore approached drawings as though they could represent complete intentionality, established in part by the particular way in which I framed the problems which the drawings aim to resolve. I took this theoretical stance itself in terms of our consensual approach to drawing. I brought material form and social situation into a now wholly theoretical framing of the drawings, bringing subjectivity into view. In this way, I established a theoretical framework in which I could produce drawings theoretically by enabling myself to consider the medium and activity of drawing as theory, not solely as theoretically objectified content.

The theoretical problem that I chose to solve considered how I might communicate with drawing the idea of the 'generalised other', that G. H. Mead writes is a prerequisite of intersubjective relationships (Mead, 1967).

Mead's 'generalised other', I should explain, is a socially shared typification of people and their actions, in which the typification itself is seen as a fully realised subject. As such, the 'generalised other' is a social definition of genre. 
However, here I want to scrutinise my process as a relationship between research and practice, rather than the specific theoretical problem itself, so I shall leave G. H. Mead aside and describe my process.

I drew three new comic strips (Figure 1, Figure 2 and Figure 3). In each case, I used the same short script extrapolated from a comic strip by artist Jim Medway (Medway, 2007:06, 07). From this script, I drew a page in the manner that a commercial comic book artist of the 1950s might have made the drawing, a page in the manner of an artist of the 1960s and a page in the manner of an artist of the 1970s.

To do this, I had to conduct a wide-ranging formal analysis of period comics, their production and milieu, to arrive at a typification of form or, in Mead's terms, a generalisation. More than this, however, I had to use this typification as a set of rules with which to constrain my own drawing. I am, after all, not a commercial comic artist either of the 50s, 60s or 70s. I operate under different constraints in a different time and place. In other words, I attempted to constrain my own subjectivity according to a theoretical typification, and then draw within the subjective constraints of that typification, rather than those conditions that habitually constrain my own drawing.

These drawings do not illustrate an independent text as adjuncts to theoretical content. Neither does the thesis that they embody require any theorising paratext in order to be understood. Rather their form itself frames questions, if their form is taken to include the material of which they are made and the explicit situations in which they are made and seen. Expressive forms, including drawing and writing, are only meaningful relative to the social environments in which they develop. According to linguists Douglas 
Biber and Susan Conrad (2009:06), comprehension of every communications register begins with the identification of what they term the register's 'situational characteristics' (200:36). These characteristics are as much social as material or, rather, they are of course the material characteristics of the register, but these are only meaningful in relation to the social context in which they appear. They are socially discursive and dialogic. Biber and Conrad claim that before a register can be identified or expressive content considered, viewers and readers undertake a sociology of the text.

A key 'situational charcteristic' of these drawings is my self-conscious use of prior knowledge of the differences that exist between an artist drawing in 2010 and the output of an artist of the mid 1950s, the mid 1960s and the mid 1970s. In doing this, the drawings precisely position the viewer. This in turn creates their theoretical argument: in summary, these are contemporary drawings that utilise the stylistic traits of three past periods. The drawings are presented simultaneously, suggesting that this range of stylistic traits cannot be ascribed as habitual to the artist. Rather, these traits have been selfconsciously adopted. However, neither are the traits identifiable as the traces of other specific artists. Rather they literally represent a series of generalisations of traits as their thesis, leaving a viewer to adjudicate the levels of competence in generalising a past period of time accurately or inaccurately, and to consider these levels of competence relative to the contemporary moments in which the drawings were actually made. The drawings do not function as theoretical text functions, because the material and the situation of their production and reception is agreed to be a part of what they communicate. In fact, these drawings are completely meaningless if these aspects 
are ignored.

With theoretical text, the form and situation of the text is consensually ignored in favour of an objectified content alone. This is one of the possible agreed conventions of research. With theoretical drawing, on the other hand, the relative subjectivity of producers and readers requires the consideration of alterity as an aspect of what is communicated, represented in the material and situation of the whole work. As a result, the entire form of a theoretical drawing communicates content by making explicit the particular relationships between intentionality and alterity that the genre of theoretical text, as an agreed convention of research, does not.

\section{References}

Allison, B. (1988) 'Research in Art and Design: research problems, programmes and debates' The Matrix of Research in Art and Design Education, London: The London Institute.

Barrett, E. and Bolt, B. (2010) Practice as research: Approaches to Creative Arts Enquiry, London: I B Taurus.

Barker, M. (1989) Comics: ideology, power and the critics, Manchester: Manchester University Press.

Biber, D. and Conrad, S. (2009) Register, Genre and Style, London: Cambridge University Press.

Biggs, M (2002) 'The role of the artefact in art and design research.' International Journal of Design Science and Technology, Volume 10 Number 2. (2007) Modelling Experiential Knowledge for Research. In The Art of 
Research: research practices in art and design. Mäkelä, M. \& S. Routarinne (editors) Helsinki: UIAH

Bird, E. (2000) 'Research in Art and Design: the first decade.' Working Papers in Art and Design Volume 1.

Burling, D., Friedman, K and Gutherson, P. (2002) 'Editorial: Debating the Practicebased PhD.' International Journal of Design Science and Technology, Volume 10 Number 2.

Candlin, F. (2000) 'A proper anxiety? Practice-based PhDs and academic unease.' Working Papers in Art and Design Volume 1. (2000) 'Practice-based doctorates and questions of academic legitimacy' Journal of Art \& Design Education Vol 19, No 1.

Candy, L. (2006) 'Practice-based research: A Guide' Creativity and Cognition Studios Report $\mathrm{Vol}$ 1,0.

Cornock, S. (1988) 'Using Research Tools in a School of Fine Art' The Matrix of Research in Art and Design Education, London: The London Institute.

Coyne, R. and Triggs, J. (2007) 'Training for Practice-Based research: Adaptation, Integration and Diversity' Creativity of Conformity: Building Cultures of Creativity in Higher Education, Cardiff: University of Wales Institute.

Cross, N. (2000) 'Designerly Ways of Knowing: Design Discipline versus Design Science' Design Plus Research Conference Proceedings, Milan: Politecnico di Milano.

Douglas, A, Scopa, K. and Gray, C. (2000) 'Research throught practice: positioning the 
practitioner as researcher' Working Papers in Art and Design Vol 1.

Evans, S. and Le Grice, M. (2001) 'The State of the Art: Research in Practical Arts Doctorates - Autonomous Methogologies' European Journal of Arts Education Vol 3, No2 and 3.

Frayling, C. (1993) 'Research in Art and Design' Royal College of Art Research Papers Vol 1, No 1.

Gray, C. and Mallins, J. (1993) 'Research procedures/Methodology for Artists and Designers' Principals and Definitions, Winchester: Winchester School of Art.

Lévinas, E. (1970) Alterity and Transcendence, New York: Columbia University Press. Madden, M. (2007) 99 Ways to Tell a Story: Exercises in Style, London: Jonathan Cape. Mead, G. H. (1967) Mind, Self, Society, Chicago: University of Chicago Press. MacLeod, K. (1998) 'Research in Fine Art: theory, judgement and discourse', Drawing Fire: The Journal of the National Association for Fine Arts Education, Volume 2, Number 2.

McCloud, S. (1993) Understanding Comics: The Invisible Art, New York: Harper Collins.

Medway, J. (2007) Teen Witch, Buxton: Paw Quality Comics.

Newbury, D. (1996) Research Perspectives on Art and Design, Birmingham: University of Central England.

Pakes, A. (2004) 'Art as Action or Art as Object? The Embodiment of Knowledge in Practice as Research' Working Papers in Art and Design Vol 3.

Quinn, M. (2007) 'Practice-led research and the Engagement with Truth' Reflections on 
Creativity: Exploring the Role of Theory in Creative Practices, Dundee: Duncan of Jordanstone College.

Rust, C., Mottram, J. and Till, J. (2007) AHRC Research Review: Practice-led Research in Art, Design and Architecture. London: Arts and Humanities Research Council.

Schön, D. (1987) Educating the Reflective Practitioner, San Francisco: Jossey-Bass.

Scrivener, S. (2000) 'Reflection in and on action and practice in creative-production doctoral projects in art and design' Working Papers in Art and Design Vol 1.

Scrivener, S. and Chapman, P. (2004) 'The Practical Implications of Applying a Theory of Practice-based Research to Art and Design' Working Papers in Art and Design Vol 3.

Smith, H. and Dean, R. (2009) Practice-based Research, Research-led Practice in the Arts, Edinburgh, Edinburgh University Press.

Snodgrass, A. and Coyne, R. (2006) Interpretation in Architecture: Design as a Way of Thinking, London: Routledge.

Sikoryak, R. (2009) Masterpiece Comics, Montreal: Drawn \& Quarterly. 